\title{
PERBEDAAN PERKEMBANGAN MOTORIK BAYI PASCA PEMBERIAN STIMULASI PIJATAN DAN BERENANG
}

\author{
The DIFFERENCE in the DEVELOPMENT of the INFANT'S MOTOR after GRANTING \\ STIMULATION MASSAGE and SWIMMING
}

\begin{abstract}
Aryunani $^{*}$, Pipit Festi Wilianarti ${ }^{2}$
${ }^{1,2}$ Universitas Muhammadiyah Surabaya,Jl. Sutorejo no 59,Surabaya, 60113, Indonesia

Informasi Artikel:
Diterima: Oktober 2015
Disetujui:
Kata kunci:
Metode Swimming and
Message
Perkembangan motorik
Keyword:
Massage, swimming, motor
development

ABSTRAK

Gangguan pertumbuhan perkembangan pada balita akan berakibat pada penurunan pembentukan sikap dan perilaku anak pada masa selanjutnya. Gangguan ini dapat dicegah dengan memberikan stimulasi perkembangan.

Desain penelitian ini adalah Quasy Eksperimental Design dengan jenis rancangan Non Equivalent Control Group. Penelitian ini dilaksanakan selama 4 bulan di Bidan Praktik Mandiri di Kelurahan Sidotopo Kec Semampir Surabaya Utara dengan sampel bayi usia 6 sampai 12 bulan. Teknik Pengambilan sampel menggunakan consecutive sampling Pengumpulan data dilakukan melalui observasi dengan menggunakan lembar observasi. Teknik analisis data menggunakan uji Wilcoxon test untuk melihat perbedaan motorik kasar sebelum dan sesudah perlakuan. Hasil penelitian menemukan bahwa $40 \%$ bayi mengalami peningkatan 1-2 segmen perkembangan motorik dan $60 \%$ bayi mengalami peningkatan perkembangan 3-4 segmen.
\end{abstract}

\begin{abstract}
Developmental growth disorders in children under five will result in a decrease in the formation of attitudes and behavior of children in the future. These disorders can be prevented by stimulating development. This study used a quasy experimental design. This research was carried out for 4 months in Privately Practising Midwives in Sidotopo village of Semampir sub-district of North Surabaya with a sample of infants aged 6 to 12 months. Data sampling used consecutive sampling collected through observation using the observation sheet. Data were analyzed using Wilcoxon test to see the difference in gross motor before and after treatment in the treatment group. In the treatment group $40 \%$ infant experienced an increase of 1-2 segment of motor development and 60\% had an increase of 3-4 segments.
\end{abstract}

\section{PENDAHULUAN}

Pemberian stimulasi untuk merangsang anak mencapai tumbuh kembang optimla pada masa anak merupakan suatu hal yang sangat penting, yang sering diabaikan oleh orang tua. Biasanya penanganan lebih banyak difokuskan pada mengatasi penyakitnya, sementara tumbuh kembangnya diabaikan. Setelah anak sembuh dari sakitnya, yang sering terjadi adalah justru timbulnya masalah yang berkaitan dengan tumbuh kembangnya, misalnya, anak mengalami kemunduran dalam kemampuan otonominya.

Situasi ini sangat berbeda dengan pendapayan sebagian besar orang tua yang

* Korespondensi penulis. aryunhadi@gmail.com menganggap bahwa selama anak tidak sakit, hal ini berarti bahwa anak tidak mengalami masalah. Perkembangan fisik sangat berkaitan erat dengan perkembangan motorik anak. Masalah gangguan perkembangan motorik dapat dicegah dengan memberikan stimulasi motorik sejak usia dini. Salah satu stimulasi yang dapat dikembangkan adalah dengan melakukan massage and swimming method.

Data kesehatan bayi yang mengalami gangguan pekembangan adalah $8,45 \%$ (Dinas Kesehatan Provinsi Jatim, 2013) Penelitian ini bertujuan untuk (1) mengidentifikasi pemberian massage and swimming method pada bayi 6-12 bulan, (2) mengidentifikasi tingkat perkembangan motorik pada bayi sebelum dan sesudah diberikan metode swimming dan message pada bayi 6-12 
Berenang merupakan sebuah kegiatan yang popular, dimana dari bayi nol tahun sudah dapat melakukannya. Bagi bayi sendiri, berenang merupakan olah raga yang menggunakan hampir seluruh bagian otot yang ada pada tubuh mereka. Olah raga ini cocok bagi semua usia, dari bayi hingga lansia, karena berenang memberikan pengaruh rasa nyaman bagi yang melakukannya. Olah raga didalam air ini memberikan sensasi tersendiri karena karena membuat seseorang menjadi rileks dan bugar.

Pijatan adalah sentuhan tertentu yang memiliki efek terapi dan stimulasi. Pijatan pada bayi yang dilakukan secara rutin oleh orang tua akan membawa efek positif melancarkan tekanan darah dan meningkatkan kualitas komunikasi (bounding antara ibu dan bayi).

\section{METODE PENELITIAN}

Penelitian ini adalah penelitian Quasi Eksperimental. Sampel penelitian ini adalah bayi usia 6-12 bulan.

Data penelitian adalah data primer, yaitu data yang diperoleh langsung dari hasil observasi terhadap responden (bayi usia 6-12 bulan) sebanyak 30 bayi. Pengambilan sampel menggunakan tehnik probability sampling dengan cara Consecutive Sampling. Pengambilan data dilakukan di salah satu bidan praktik mandiri di Kelurahan Sidotopo Kec. Semampir Surabaya yang dilakukan selama 4 bulan. Pengambilan data menggunakan teknik observasional, dan kemudian dianalisis secara deskriptif dan analitik.

\section{HASIL DAN PEMBAHASAN}

\section{Tabel 1: Usia Bayi dalam bulan}

\begin{tabular}{ccc}
\hline Usia Bayi & $\mathbf{N}$ & $\mathbf{( \% )}$ \\
\hline $6-8$ & 22 & 73.3 \\
\hline $9-11$ & 8 & 26.7 \\
\hline Total & $\mathbf{3 0}$ & $\mathbf{1 0 0}$
\end{tabular}

Berdasarkan data pada tabel 1, bayi usia 6-8 bulan adalah sebanyak $73.3 \%$, sedangkan sebagian kecil berusia $9-11$ bulan
Tabel 2: Perbandingan Perkembangan Motorik Sebelum dan Sesudah Massage and Swimming Methods pada kelompok perlakuan

\begin{tabular}{lcccccc}
\hline & \multicolumn{6}{c}{ Perkembangan Motorik } \\
\cline { 2 - 7 } Kelompok & $\begin{array}{c}\text { Sesuai } \\
\text { Perkembang } \\
\text { an }\end{array}$ & $\begin{array}{c}\text { Peningkatan 1-2 } \\
\text { Segmen } \\
\text { perkembangan }\end{array}$ & $\begin{array}{c}\text { Peningkatan } \\
\text { 3-4 segmen } \\
\text { Perkembangan }\end{array}$ \\
\hline Sebelum & $\mathrm{n}$ & $\%$ & $\mathrm{n}$ & $\%$ & $\mathrm{n}$ & $\%$ \\
\hline Sesudah & 0 & - & 6 & 40 & 9 & 60 \\
\hline Wilcoxon $\boldsymbol{\alpha}=\mathbf{0 , 0 5} \mathbf{p = 0 , 0 0}$ & & 3 & 20 & 0 & - \\
\hline
\end{tabular}

Berdasarkan Tabel 2, perkembangan motorik bayi sebelum dilakukan pemijatan dan latihan renang adalah bahwa 12 bayi (80\%) berkembang sesuai dengan usianya, sedangkan 3 bayi (20\%) mempunyai perkembangan motorik yang meningkat sebanyak 1-2 segmen. Enam bayi (40\%) mempunyai perkembangan motorik dengan peningkatan 1-2 segmen, dan 9 bayi (60\%) mengalami peningkatan 3-4 segmen dalam sektor perkembangan motorik. Perlakuan massage dan swimming dilakukan $8 \mathrm{x}$ dengan interval waktu 2 minggu selama 4 bulan, dan evaluasi pada bayi dilakukan pada 2 minggu setelah diberikan tindakan. Berdasarkan uji Wilcoxon didapatkan hasil $\alpha=0,05 p=0,00$, yang berarti bahwa pemberian stimulasi massage dan swimming mempunyai pengaruh terhadap perkembangan motorik pada bayi usia 6-12 bulan.

Dalam penelitian ini dapat diketahui bahwa pengaruh yang signifikan stimulasi Metode Swimming and Massage terhadap perkembangan motorik optimal bayi usia 6-12 bulan. Hasil penelitian ini dapat digunakan para orang tua untuk melakukan stimulasi dini dalam mencegah gangguan pertumbuhan dan perkembangan bayi, terutama dalam perkembangan motorik bayi. Sering terjadinya sakit akan menggangu perkembangan bayi.

Berdasarkan Wenche (2010) dijelaskan bahwa pengetahuan ibu yang kurang tentang stimulasi dini memiliki risiko bayi yang lebih tinggi untuk terjadi keterlambatan perkembangan motorik dibandingkan dengan kelompok anak dengan pengetahuan ibu yang baik. Gangguan 
sentuhan ibu atau keluarga terhadap bayinya akan menyebabkan penurunan enzim ODC (ornithine decarboxylase) dan peningkatan pengeluaran neurochemical betha-endorphine, sehingga akan mempengaruhi perkembangan bayi. Dalam penelitian tersebut disebutkan bahwa renang pada bayi akan menurunkan risiko terjadinya infeksi saluran pernafasan. Infeksi saluran pernafasan adalah penyakit yang sering terjadi pada bayi yang dapat mempengaruhi perkembangan bayi tersebut.

Pada masa bayi, anak mengalami masa keemasan (the golden years) yang merupakan tahap saat anak mulai peka dan sensitif untuk menerima berbagai rangsangan. Pada masa peka inilah, bayi mulai matang secara fisik dan psikisnya, sehingga siap merespons stimulasi yang diberikan oleh lingkungan. Pengetahuan ibu tentang stimulasi dini bayi sangat penting untuk perkembangan motorik optimal, karena dengan sentuhan, bayi akan merasa nyaman dan hal ini akan menjalin ikatan emosional yang tercipta secara alami. Selain sentuhan pijat, berenang juga dapat merangsang saraf-saraf motorik bayi agar tumbuh kembangnya optimal.

\section{KESIMPULAN}

Dengan stimulasi swimming dan massage dilakukan pada bayi usia 6-12 bulan, kelompok kontrol menunjukkan peningkatan 1-2 segmen perkembangan motorik dan kelompok perlakuan mengalami peningkatan perkembangan motorik 34 segmen perkembangan.

\section{DAFTAR PUSTAKA}

Dinas Kesehatan Provinsi Jawa Timur. 2013.

Nirmala, dkk.2010. Fisiologi dan Patologi.Jakarta. EGC

Nursalam. 2003. Konsep dan Penerapan Metodologi Penelitian Ilmu Keperawatan, Pedoman Skripsi, Tesis Dan Instrumen Penelitian Keperawatan. Jakarta : Salemba Medika.

Notoatmodjo, Soekidjo. 2005. Metodologi Penelitian Kesehatan. Jakarta : PT Rineka Cipta.

Sugiyono. 2004. Metodologi penelitian administratif. Bandung: Alfabeta
Syaukani Aulia, 2015. Pijat, Senam dan Yoga Sehat untuk Bayi. yogyakarta. araska.

Halimah A. 2012. Pengaruh Stimulasi Bayi terhadap Perkembangan Motorik Kasar pada bayi usia 3 - 8 Bulan. Media Kesehatan. Vol V no 1.

Wenche Nystad1, Siri E. Håberg1, Stephanie J London2, Per Nafstad1,3, and Per Magnus1. 2010. Baby swimming and respiratory health. PMC. 14 September. 9 